Title: Genomic Sovereignty and the African Promise: mining the African genome for the benefit of Africa

Keywords: Africa, genomics, ethics sample export, genomic sovereignty, collaborative global health research

Word Count: 3569 


\title{
Genomic Sovereignty and the African Promise: mining the African genome for the benefit of Africa
}

\begin{abstract}
Scientific interest in genomics in Africa is on the rise with a number of funding initiatives aimed specifically at supporting research in this area. Genomics research on material of African origin raises a number of important ethical issues. A prominent concern relates to sample export, which is increasingly seen as being problematic by researchers and ethics committees across the continent. The concept of genomic sovereignty proposes that unique patterns of genomic variation can be found in human populations, and that these are commercially, scientifically or symbolically valuable and in need of protection against exploitation. Although it is appealing as a response to increasing concerns regarding sample export, there are a number of important conceptual problems relating to the term. It is not clear, for instance, whether it is appropriate that ownership over human genomic samples should rest with national governments. Furthermore, ethnic groups in Africa are frequently spread across multiple nation states and protection offered in one state may not prevent researchers from accessing the same group elsewhere. Lastly, scientific evidence suggests that the assumption that genomic data is unique for population groups is false - although the frequency with which particular variants are found can differ between groups, such genes or variants per se are not unique to any population group. In this paper, we describe these concerns in detail and argue that the concept of genomic sovereignty alone may not be adequate to protect the genetic resources of people of African descent.
\end{abstract}

\section{Introduction}

In recent years there has been an explosion in the use of genomics methods to study common complex diseases. However, such research remains largely dominated by researchers in affluent parts of the world, and is biased towards populations of European descent. For instance, Rosenberg et al and Need et al found that between $75 \%$ to $90 \%$ of genome wide association studies published up to 2010 were conducted on populations of European descent, with the remainder conducted primarily on populations of Asian descent.[1, 2] Only a small minority of studies have focused on populations of African descent. Cutting edge scientific methodologies seem to reinforce - not address - existing global health inequalities.[3] In order to ensure that any potential benefit of genomics research for health is distributed less unequally across the world's populations, it is of paramount importance that genomics research methodologies include populations in the poorer parts of the world, including Africa.

However, historically, scientific engagement with African participants and scientists has not primarily benefited people on the African continent. Rather, the trend has been to use data derived from African populations to build research programs and enhance individual careers in more affluent communities with little or no consideration for the populations from which this material was derived.[4]

The concept of 'genomic sovereignty' appears to have emerged in response to growing discontent with the organization of global health research, and it refers to a perceived need for protection of genomic resources of low-income countries against exploitation by entities based in wealthier countries.[5] It has steadily been gaining support from researchers and ethics committee members across the African continent in the hope that it can ensure that genomics research done on the African continent becomes more fair to African science and scientists and is of benefit to African research participants. 
In this paper, we will explore whether the concept of genomic sovereignty is likely to achieve this goal. We will first offer a short introduction to the current state of genomics research on the African continent, followed by a description of what 'genomic sovereignty' is understood to mean in the literature. We will then identify and discuss a number of conceptual problems with the term which, we argue, make it ill-suited to achieve the aim of stimulating a less unequal African science. First, we will question the assumption that the nation state is the appropriate authority to govern genomic resources on behalf of populations living within its confines. Second, we will discuss the observation that ethnic groups often live across multiple nation states and examine the implication of this observation for the concept of genomic sovereignty. Third, we will critically examine the assumption that genomic material is unique for populations by looking at current scientific evidence. Last, we will question the notion that nationalistic science is morally superior to international science, which seems to lie at the basis of some of the discussions about genomic sovereignty.

\section{Genomics 'in Africa, for Africa, by Africans'}

A number of genomics research initiatives have recently been launched with the apparent objective of addressing the global genomics inequity gap, and establishing a genomics research agenda based on the principles of equity and mutual benefit. The most prominent of these initiatives is the H3Africa project, a collaborative funding initiative by the Wellcome Trust in the UK and the NIH in the US.[6] This project is said to be 'refreshingly ethical'[7] in its ambition to stimulate genomics research on the African continent.

Genomics research involving African institutions tends to occur in the context of large-scale export of samples from the African continent towards scientific institutions in more affluent parts of the world. [8] Such research collaborations tend to have limited benefit for research participants, researchers and institutions in African countries. For instance, a recent study investigating all human genetic studies published in between 1989 and 2009 found that only a small number of African researchers and institutions were involved compared to international collaborators, and that the topics of research did not match the health priorities as set by the Cameroonian government.[9] Concerns about the reasons for and the implications of sample export in genetics are increasingly widespread $[5,10,11]$. In particular on the African context, fears about a revival of colonialist relations between Africa and the Western world seem at least in part to underlie such concerns [12].

Against this background, calls have been made for a genomics science that should be 'in Africa, for Africa, by Africans'.[13] The emergence of the concept of genomic sovereignty seems to fit this notion by offering a conceptual framework for how genomics research on African patients could be ensured to be more African. It does so primarily by regulating the ownership of genomic material and samples. In this paper, we will highlight several conceptual problems with the notion of genomic sovereignty which, we believe, make it ill-suited to promote fairer and optimally beneficial genomic research in Africa.

\section{Defining the concept of genomic sovereignty}

One response to the issues raised above is the emergence of the concept of 'genomic sovereignty'. This term was originally framed by Mexican legislators seeking to ensure ownership over Mexican human genetic resources, and was a response to concerns over possible piracy of human genomic resources by foreign entities, in connection with a growing realisation that human genomic variation could hold both scientific and commercial value.[5] It rests on the fundamental premise that "unique patterns of genomic variation are sovereign resources and should be protected from foreign prospectors".[5: 490] In the view of Seguin and colleagues, the concept is a way for countries to "leverage" the human 
genomic variation in their population(s), in order to "encourage local innovation and participate as equal partners in the global knowledge-based economy".[5: 490]

Slabbert and Pepper seem to support such a view. For them, the concept is a promising way to end years of frustration of seeing samples exported with limited or no benefit to the South African population.[14] These authors define genomic sovereignty as "the capacity of a people, a country or nation to own, to control both access to and use of, samples, data and knowledge concerning or emanating from genomic material".[14: 436] This definition encapsulates all genomic material, regardless of its origin. As such, it includes human, animal, microbial and plant genomic material. Recent advice to the South African government was to incorporate the notion of genomic sovereignty into law in the form of benefit sharing and material transfer agreements, and the current revision process of Chapter 8 of the National Health Act (no. 61 of 2003) in South Africa may provide a possibility that this concept is incorporated into law in at least one African country.

For Ruha Benjamin, however, the concept is something quite different than a means of empowerment.[15] In her view, engagement with the concept of genomic sovereignty is largely motivated by a deeply nationalist attempt to capture the economic promise of the genomic diversity of populations living within a country. Benjamin argues that genomic sovereignty may be a project designed to benefit those already in power, and could perhaps lead to further exploitation of indigenous peoples living within the confines of particular nation states.

One basic premise underpinning the idea of genomic sovereignty is that human genomic material is a valuable resource, where value is both of a commercial and a symbolic nature. In the commercial sense, the expectation is that the discovery of unique patterns of genetic predisposition could provide targets for drug development and the development of novel diagnostic tools, both of which have the potential to generate revenue for the entities involved. In the symbolic sense, genomic material is seen to be representative of the population groups in a country. Just like other natural resources, genomic resources are seen to be in need of protection from exploitation. As a symbolic concept, genomic sovereignty is certainly appealing, and if enshrined in law, could regulate the flow of human samples from Africa to other parts of the world and possibly provide a means for control over samples once abroad. As such, it could indeed act as a tool to empower nations in poorer parts of the globe, and promote genomics research that is truly 'in Africa, for Africa, by Africans'. However, despite its appeal, we believe that there are a number of very important conceptual issues that need to be addressed.

\section{Who holds the 'ultimate authority' over genomic material?}

Sovereignty is broadly defined as the need for a source of uncontested power of final decision in a system of government. In other words, in a nation state there needs to be an institution, governance body or person that holds the right to make final decisions. By logical extension, genomic sovereignty would signify that there should be a source of final authority that can decide what happens to and with genomic material. For other biological or natural resources, such as a country's mineral resources or indigenous plants, it may be appropriate that the state is awarded sovereign power - although even in that case, the interests of local communities and populations and those of the government often clash. For human genetic resources, however, it is not clear whether it is appropriate that the national government should hold final authority. Other authorities may also wish to have a say. For instance, careful thought needs to be given to the role of the person from whom the sample is collected and therefore becomes a part of the genomics study. One of the central principles of research ethics today is autonomy, which suggests that individuals have a right to decide what happens to their bodies or components thereof. This right is virtually inalienable and can be taken away only under specific 
circumstances, such as for instance the loss of mental capacity. Although the right to exercise control over one's body does not automatically extend to a right to control what happens to tissues taken from the body,[16] supporters of the concept of genomic sovereignty need to consider the implications for autonomy in their recommendations.

Another assumption is that the national government - and not other institutions within a country - is best suited to protect the interests of the population groups within its borders. The assumption is that the nation state will equally protect the interests of all populations in a country. In South Africa, as in many other countries, history evidently demonstrates that this is not always true.

The argument that the groups from whom biological material is taken should retain some authority over (subsequent use of) this material is most often made in the context of research on indigenous peoples. However the view that ethnic groups should also exercise some authority over their genomic material is problematic in its own right. One question, for instance, is who is the relevant authority to speak on behalf of the ethnic group? 'Ethnic groups' on the African continent are not easily defined.[17] Ethnic groups can (a) be defined on the basis of language; (b) be an administrative category established during colonial times; (c) be historical entities with well established culture and traditions, and (d) be relatively new groups formed in response to changing demographics on the continent. They can be small or very large, located in a well-defined area or spread out over several countries. Exactly which of these units should count as 'autonomous' is not entirely clear.

\section{Ethnic groups, Diaspora and the boundaries of the nation state}

The assumption that national governments are well-placed to protect the genetic resources of the populations in a country also poses a problem in that it presumes that there is an overlap between the boundaries of the nation state and the geographical boundaries of ethnic groups. In Africa, this is often not the case. For instance, (descendants of) the San people live across Namibia, Botswana and South Africa. Similarly, people of the Yoruba ethnic group originally lived in an area spread out over modern Nigeria, Benin, Togo and Ghana, but there are now also large populations of Yoruba in Europe and the United States.[18] That one country protects the genomic material of a particular group may mean researchers find genetically similar people in other countries with less strict protection. It also complicates claims about national ownership of genomic material. If the ambition of adopting the concept of genomic sovereignty into law is to protect the population groups within a country, then the spread of groups across countries would require the harmonisation of policies and laws across those countries.

If there is no intention to harmonise policies and laws across countries to offer full protection against 'bioprospectors', then the question is whether the incorporation of the concept of genomic sovereignty into law would really protect the interests of different population groups within a country, or rather the interests of the nation state. A concern would be whether governments would be equally incentivised to protect all the population groups in a country. Where one particular population group is in power, it could be that the interests of that population group will first and foremost be protected. Similarly, if particular population groups are already marginalised in a particular state, then it is possible that the concept of genomic sovereignty would not award any additional protection against scientific exploitation to these groups.

\section{Genetic variants, genomic data and the quest for sovereignty}

The concept of genomic sovereignty also raises a number of issues from a scientific perspective. The first relates to the claim - central to the notion of genomic sovereignty - that there is something unique 
about the genomic material of populations that is in need of protection. The assumption seems to be that researchers will discover genomic sequences or variants that a) are unique for particular population groups, and b) are of commercial, scientific or symbolic value. This claim is problematic because genomic material is, essentially, shared between humans, and no genetic variants have yet been discovered that are unique to a given population group. The closest candidate for such a role is a genetic variant in the coding region of the gene for the so-called Duffy antigen.[19] Mutations in the antigen coding region account for a change in the structure of haemoglobin, which in specific circumstances renders erythrocytes impenetrable to a particular malarial parasite. The Duffy Antigen mutation is found primarily in Africans and could therefore arguably be used to identify people of African ancestry. However, the variant has also been found in populations in other parts of the world, making it ill-suited for that purpose. No other genetic variants or sequences that designate population groups with relative accuracy have been identified to date.

There is, however, increasing evidence that (a) variants may occur at different frequencies in different population groups and (b) particular combinations of genomic variants could function as reasonably accurate predictors of disease in specific population groups,[20] in the same way that product bar codes allow for the precise identification of the nature and source of a product. Although none of the numbers on a bar code would uniquely identify a product in their own right, the particular combination of numbers on a bar code does. Similarly, although there are no individual genetic variants that could identify population groups, there are certainly combinations of genetic variants and the frequencies at which they occur that could act as signatures for particular population groups. A crucial difference between bar codes and genetic signatures, however, is that the latter do not uniquely identify population groups. The genetic variants identified in genomic studies are usually carried only by a percentage of people from a particular ethnic group and not by all individuals.

If arguments in favour of genomic sovereignty rest on the assumption that genetic material is in need of protection because it is unique to population groups, then the case for genomic sovereignty seems to be weakened by the scientific evidence. Genomic information is not unique for population groups or for people in a particular country. This leaves an important challenge as to the means and justifications for offering protection to a nation's human genetic resources - namely, what is it that should be protected?

This leads us to our second concern, which relates to the practical distinction between genomic material and genomic data. Once genomic material has been sequenced or genotyped, the sample itself is no longer essential for genomic studies. The concept of genomic sovereignty does not seem to consider genomic data, however, which could still travel freely across the globe analysis.

\section{The importance of doing good research}

It may well be that information derived from research on the genome of African populations could positively impact on the health of individuals on the African continent. If that is the case, then what is important is that such benefits are achieved as efficiently and timely as possible and in the appropriate setting - regardless of where the research takes place. Within this framework however, several less tangible but equally important issues need to be addressed.

The first recognizes that there is a duty to invest in health research that will benefit one's own population. In order for the research to be relevant and the fruits thereof to be applied in an appropriate manner, members of the population in question should be involved. In order to do this, investment into the development of local capacity is of paramount importance. However, this may (and usually does) require input from nations that possess technology and know-how that is more sophisticated and cutting-edge than the country requiring the investment. Once the limits of 
philanthropy and social good have been exceeded, some return will be expected from the investor, which is usually a wealthier country. Legislation that is restrictive in nature and that does not make room for meaningful collaborations will discourage much needed investment into the development of local capacity.

The second issue relates to the question of ownership. Since the sovereign nature of genomic material is difficult to define accurately, bilateral agreements that relate specifically to the more practical matters of access to data and benefit sharing (for example through a well-structured material transfer agreement) should be given precedence over a strict adherence to the notion of ownership. The quality of research and the application of the outcomes thereof should not be compromised in the interest of determining ownership.

\section{Genomic sovereignty and its role in African genomics research}

Benatar and Singer propose that all global health research, which includes genomics research, ought to be driven by principles of equity, beneficence and social justice.[21] We propose that discussions about genomic sovereignty may hamper an attempt - by stakeholders within and outside Africa - to ensure that genomics research is more equitable and just. For the reasons outlined in this paper, we contest the notion that a focus on the ownership of genomic material alone is sufficient to achieve more just and equitable genomics research. If, as we believe, stakeholders in genomics research share a common vision of a more just, equitable and beneficial genomics research on the African continent, then the task at hand is to identify the values, laws and processes that will ensure that these objectives are met. In this paper, we have outlined what we see as fundamental limitations to the concept of genomic sovereignty that render it inadequate to address concerns about inequality in genomic research on its own. We have questioned the assumption that the nation state is the appropriate authority to govern genomic resources on behalf of populations living within its confines; we have noted that the populations whose material should be protected, often live across multiple countries thereby rendering the idea that one nation state should control the genomic material of a population group ineffectual; we have criticised the assumption that genomic material is unique for populations by looking at current scientific evidence (although we do recognise that variant frequencies may vary), and we have questioned the assumption that nationalistic science is morally superior to international science.

Instead, we suggest that solutions to the perceived inequality and unfair distribution of benefit that is problematic in international collaborative genomics research need to be more directly aimed at addressing the problems. Specifically, if the problem is unequal benefit for partners and countries in collaborations, then stakeholders in research should strive to develop governance tools that ensure a fairer distribution of benefit. An example is the development of a data release policy for a genomics research initiative that specifically aims to take into account the challenges faced by researchers working in resource-poor institutions.[22] Also important are issues such as African leadership in setting research agendas and project management and fair opportunities for African researchers to lead analyses and the preparation of manuscripts for publication. Similarly, the related issues of capacity building and sustainability will also need to be addressed if genomic research on the African continent is to be truly beneficial for African research participants and researchers.[8] Lastly, if the problem is sample export, then researchers, governments and ethics committees based in lower-income countries should work together to regulate sample export in a way that is satisfactory to all concerned. Detailed material transfer agreements which address the notion of benefit sharing seem to be one important way that this could be achieved [23, 24]. However, we believe that 'owning' African genomics is not only a right, but also a responsibility that African genomics researchers must assume, in order to harness the potential of 
African genomic material to address diseases affecting patients on the African continent and elsewhere.[8, 22-24]

\section{References}

1. Need AC, Goldstein DB. Next generation disparities in human genomics: concerns and remedies. Trends in Genetics 2009;25:489-94.

2. Rosenberg NA, Huang L, Jewett EM, et al. Genome-wide association studies in diverse populations. Nat Rev Genet 2010;11:356-66.

3. Newport MJ, Rotimi CN. Reducing the Global Genomic Inequity Gap: Development of an African Genome Project. Public Health Genomics 2009;12:251-2.

4. Pang T. Global health and research: changing the agenda. In: Benatar SR, Brock G, editors. Global Health and Global Health Ethics. Cambridge: Cambridge University Press; 2011. p. 285-92.

5. Seguin B, Hardy B-J, Singer PA, et al. Genomic medicine and developing countries: creating a room of their own. Nat Rev Genet 2008;9:487-93.

6. H3Africa Working Group. Harnessing Genomic Technologies Toward Improving Health in Africa: Opportunities and Challenges. Recommendations for the Human Heredity and Health in Africa (H3Africa) Initiative to the Wellcome Trust and the National Institutes of Health2011 13 October 2011.

7. Tan T. H3Africa, a Refreshingly Ethical Research Endeavor in Africa 2010; Available from: http://www.genengnews.com/blog-biotech/h3africa-a-refreshingly-ethical-research-endeavor-inafrica/620/.

8. De Vries J, Bull S, Doumbo OK, et al. Ethical Issues in Human Genomics Research in Developing Countries. BMC Medical Ethics 2011;12.

9. Wonkam A, Kenfack MA, Muna WFT, et al. Ethics of human genetic studies in Sub-Saharan Africa: the case of Cameroon through a bibliometric analysis. Developing World Bioethics 2011;11:120-7.

10. Chatterji S, Jain S, Brahmachari SK, et al. International collaboration in genetics research. Nat Genet 1997;15:124-.

11. Langat SK. Reuse Of Samples: Ethical Issues Encountered By Two Institutional Ethics Review Committees In Kenya. Bioethics 2005;19:537-49.

12. Van Rinsum H, Tangwa GB. Colony of genes, genes of the colony: diversity, difference and divide. Third World Quarterly 2004;25:1031-43.

13. Wellcome Trust. Transcript of the Human Heredity and Health in Africa Press Conference in London2010 13 October 2011.

14. Slabbert MN, Pepper M. "A room of our own?" Legal lacunae regarding genomic sovereignty in South Africa. Tydskrif vir Hedendaagse Romeins-Hollandse Reg (Journal of Contemporary South African Roman-Dutch Law) 2010;73:432-50.

15. Benjamin R. A Lab of Their Own: Genomic sovereignty as postcolonial science policy. Policy and Society 2009;28:341-55.

16. Andrews L. Who owns your body? A Patient's Perspective on Washington University v. Catalona. Journal of Law, Medicine and Ethics 2006;34:398-407.

17. Hutchinson J, Smith AD. Ethnicity. Oxford: Oxford University Press; 1996.

18. Akintoye SA. A history of the Yoruba people. Dakar: Amalion Publishing; 2010.

19. Kwiatkowski D. How Malaria has Affected the Human Genome and what Human Genetics can teach us about Malaria. American Journal of Human Genetics 2005;77:171-90.

20. Jallow M, Teo YY, Small KS, et al. Genome-wide and fine-resolution association analysis of malaria in West Africa. Nat Genet 2009;41:657-65.

21. Benatar SR, Singer PA. Responsibilities in international research: a new look revisited. Journal of Medical Ethics 2010;36:194-7. 
22. Parker M, Bull SJ, de Vries J, et al. Ethical Data Release in Genome-Wide Association Studies in Developing Countries. PLoS Med 2009;6:e1000143.

23. Ndebele P. Material transfer agreements are a "must" when transferring specimens across national boundaries. J Med Ethics 2007.

24. Andanda PA. Human-tissue-related inventions: ownership and intellectual property rights in international collaborative research in developing countries. J Med Ethics 2008;34:171-9. 